\title{
Awareness of hepatitis $B$ and $C$ among students of nonmedical universities in Karachi
}

\author{
Ali Rafiq, Saba Fatima, Beenish Masood, Rizwan Ahmed Khan, Fareeha Ahmed Khan, Aimen Liaquat, \\ Aelia Fatima, Mohammad Shahrukh Tanveer, Mahreen Sulaiman, Syed Yousuf Hasan, Mariam Aehtesham, \\ Sidra Khan \\ Dow University of Health Sciences, Karachi 74200, Pakistan
}

\begin{abstract}
Background: Pakistan is highly endemic with hepatitis B virus (HBV) and the incidence of HBV infection is rising steadily. The reasons may include poor public awareness about the transmission of HBV and HCV.

Objectives: To assess the awareness of HBV and HCV among students in nonmedical universities.

Methods: The study instrument was a structured 36 item questionnaire. After obtaining permission from the respective administrations, students were approached within their university campuses and were included by convenience sampling. The results were expressed as frequencies.

Results: Five hundred students from 5 different institutions participated in the survey, with 100 students representing each institute. Most students did not recognize the possible modes of infection of hepatitis B that include reuse of syringes (57.2\%), blood transfusions (62.6\%), and sexual contact (57.4\%). However, most (67.8\%) students correctly believe that there is a vaccination available for the prevention of HBV. Most students did not recognize the possible modes of infection of hepatitis $C$ that include reuse of syringes (61.8\%), use of intravenous drugs of addiction (71.4\%), sexual contact (55.6\%), and blood transfusions (55.2\%) as possible modes of transmission. Most students (51.8\%) incorrectly believed that there is a vaccination available for the prevention of HCV.

Conclusions: There is a prominent lack of awareness regarding the risk factors for HBV and HCV infection among the student community of nonmedical universities in Karachi, and an immediate need to conduct nationwide awareness programs to raise the awareness of HBV and HCV transmission in the Pakistani population exists.
\end{abstract}

Keywords: Hepatitis B, hepatitis C, infection, Pakistan

Hepatitis is characterized by inflammation of the liver. A group of viruses called the hepatitis viruses (A-E) cause most of the cases worldwide. Of these, hepatitis B virus (HBV) and hepatitis C virus (HCV) have become a serious problem for public health, and are a major cause of morbidity and mortality worldwide.

Serological studies indicate that more than 2 billion people have been infected with HBV worldwide [1]. This includes 350 million chronic carriers of the virus [2]. Pakistan is highly endemic with HBV [3] with 9 million people infected with the virus [4] and the incidence of HBV infection is rising steadily [5]. The reasons may include the lack of proper health facilities, poor economic status, and poor public awareness about the transmission of major communicable diseases including $\mathrm{HBV}, \mathrm{HCV}$, and

Correspondence to: Ali Rafiq, Dow University of Health Sciences, Karachi 74200, Pakistan. E-mail: alirafiq@hotmail.co.uk
HIV [6]. Pakistan lies in the "Intermediate zone" of the WHO zones of viral hepatitis. The 3 major modes of its transmission are hematogenous, sexual, and vertical. Reuse of contaminated needles and syringes is also a major source for spread. There is a high incidence of hepatocellular carcinoma associated with this infection. However, HBV infection can be prevented through vaccination.

About 200 million people are infected with HCV worldwide, which covers about $3.3 \%$ of the world's population [7, 8]. HCV infection leads to chronic hepatitis in $50 \%$ to $80 \%$ of individuals [9]. The rate of chronic carriage of hepatitis $\mathrm{C}$ virus is much higher than that of hepatitis B and more likely to occur when the virus is acquired during adulthood. In Pakistan, 5.09\% people are presumed to be infected with HCV [10]. In developing countries, blood transfusion, reuse of needles for tattooing, ear and nose piercing, reuse of syringes, injecting drug users, shaving by barbers, and use of unsterilized dental and surgical instruments 
or lack of implementation of international standards for sterilization of dental and surgical instruments, are the main source of transmission of HCV. Currently no vaccine is available to prevent HCV infection.

The purpose of the present study was to assess the awareness of students in nonmedical universities in Karachi, who represent a major portion of the student population, regarding the modes of transmission of different types of hepatitis viruses, and of basic knowledge about hepatitis.

\section{Method}

The Ethical Review Board at Dow University of Health Sciences' research department approved this research. Written informed consent was obtained from each of the participants of the study.

This was a descriptive study conducted over 4 months from June 1st to October 1st, 2013. The study instrument was a self-structured 36-item questionnaire (proforma) prepared after an extensive literature search and consultation with faculty members of the community medicine department. "Awareness" was presented based on the responses obtained through the 36-item self-structured questionnaire. The questions in the questionnaire were added on the advice of Prof. Rana Masood, a prominent gastroenterologist at the Civil Hospital, Karachi.

Besides collecting a demographic profile such as age, sex, and the university where the participant is a student, the proforma comprised "Part A" that deals with the various modes of infection with HBV and HCV and "Part B", that deals with the details of HBV and $\mathrm{HCV}$, including questions related to perceived chances of recovery, vaccinations, and screening (10 questions).

\section{Setting}

The study was conducted at the Institute of Business Management, NED University, Greenwich University, Karachi University, and Indus Valley School of Art and Architecture, in Karachi.

\section{Participants}

A total of 500 students were included by convenience sampling. We approached the students within their university campuses after obtaining permission from the respective administrations. After indicating consent, students signed a document of informed consent before completing the questionnaire.

\section{Inclusion criteria}

Undergraduate students enrolled in any of the bachelor programs offered at various private and/or government universities.

\section{Exclusion criteria}

Graduate students, students belonging to any of the programs related to health sciences and students declining to give their consent for inclusion.

\section{Statistics}

We used the sample size calculator available from Raosoft (Seattle, WA, USA) to calculate sample size based on a $5 \%$ margin of error and $95 \%$ confidence level for a population size of 130,000 and a conservative response distribution of $50 \%$. The sample size was calculated to be 384 , and our study size of 500 exceeded that number to ensure adequate power for the study.

SPSS version 16.0 (SPSS Inc, Chicago, IL, USA) was used for statistical analysis of the questionnaire responses. We have expressed the results in terms of percentage of correct responses to the questions asked in the 36-item self-structured questionnaire.

\section{Results}

A total of 500 students from 5 different institutions participated in the survey, with 100 students representing each institute. A total of 245 male and 255 female students took part in the study. The mean age of the participants was 21.6 years with a standard deviation of \pm 1.99 .

We have presented the results of the responses to the perceived modes of infection of HBV in Table 1.

Most (67.8\%) students correctly believed that there is a vaccination available for the prevention of HBV infection. Most students (56.4\%) students do not associate $\mathrm{HBV}$ with long-term disease.

The results for the perceived modes of infection of HCV are shown in Table 2.

Most (51.8\%) students incorrectly believed that there is a vaccination available for the prevention of hepatitis C. Although, most students (55.6\%) associate hepatitis $\mathrm{C}$ with long-term disease.

When asked if they had been vaccinated against any of the types of hepatitis, 247 (49.4\%) answered in the affirmative, 161 (32.2\%) said "no", and 89 (17.8\%) did not know. The remaining students did not answer the question. Of the 247 students answering 
in the affirmative, only 143 claimed to know the type of hepatitis they had been vaccinated against. Thirty (21\%) said hepatitis A virus (HAV), 81 (56.6\%) said HBV, 30 (21\%) said HCV, and 3 (2.1\%) claimed to have been vaccinated against hepatitis $\mathrm{E}$ virus (HEV). Of the 247 students who claimed to have been vaccinated against hepatitis virus, only 69 (27.9\%) claimed to know the number of doses they had received. Twelve (4.9\%) students said they received just one dose, 21 (8.5\%) students claimed to have received 2 doses, 28 (11.3\%) students said they received 3 doses, and 8 (3.2\%) students said they had received more than 3 doses.

When asked if they had undergone any blood tests for hepatitis in the past, 116 (23.2\%) students answered in the affirmative, 292 (58.4\%) students said "no", and $86(17.2 \%)$ students did not claim to know. The remaining students did not answer the question.
When asked if any of their close family members were suffering from any of the forms of hepatitis, 113 (22.6\%) students answered in the affirmative, whereas 381 (76.2\%) students denied it. The remaining students did not answer the question. Of the 113 students who answered in the affirmative, 88 (77.9\%) students knew which type of hepatitis their close family members were suffering from; 10 (8.8\%) students said HAV, 32 (28.3\%) students said HBV, 44 (38.9\%) students said HCV, and 2 (1.8\%) students said HEV. Considering the entire sample size of $500,2 \%$ students claimed to have a close family member suffering from HAV, 6.4\% students said HBV, 8.8\% said HCV, and 0.4\% said HEV.

When asked if they thought the risk factors for hepatitis and HIV are the same, 276 (55.2\%) students said "yes" and 218 (43.6\%) said "no". The remaining students did not answer the question.

Table 1. Results of the responses to the perceived modes of infection of HBV

\begin{tabular}{lc}
\hline Mode of infection & Correct response (\% of total students) \\
\hline Reused syringes & 42.8 \\
Unsterilized surgery or dentistry equipment & 41.6 \\
Sharing shaving blades or razors & 33.4 \\
Tattooing and body piercing & 35.0 \\
Intravenous drugs of addiction & 42.8 \\
Sexual contact & 42.6 \\
Blood transfusion & 37.4 \\
Drinking contaminated water & 70.8 \\
Eating contaminated food & 67.4 \\
Contact with body fluids & 38.6 \\
From a mother to her baby in the womb & 31.8 \\
From a mother to her baby through breast-milk & 39.8 \\
\hline
\end{tabular}

Table 2. Results of the responses to the perceived modes of infection of Hepatitis C

\begin{tabular}{lc}
\hline Mode of infection & Correct response (\% of total students) \\
\hline Reused syringes & 38.2 \\
Unsterilized surgery or dentistry equipment & 37.0 \\
Sharing shaving blades or razors & 36.2 \\
Tattooing and body piercing & 32.4 \\
Intravenous drugs of addiction & 28.6 \\
Sexual contact & 44.4 \\
Blood transfusion & 44.8 \\
Drinking contaminated water & 72.8 \\
Eating contaminated food & 76.2 \\
Contact with body fluids & 31.2 \\
From a mother to her baby in the womb & 30.0 \\
From a mother to her baby through breast-milk & 77.0 \\
\hline
\end{tabular}




\section{Discussion}

In the present study, only $52.6 \%$ of the nonmedical students were able to identify correctly the causes and the means of transmission of HBV. This is comparable to another survey in which 43\% [11] girls had satisfactory knowledge about the spread of HBV. It was interesting to note that only $57.2 \%$ of the students thought that HBV was spread through the reuse of syringes, which is less than the $82 \%$ calculated by a study conducted by Razi et al. [12] of university students from nonbiological sciences in Lahore. Inadequate knowledge of this mode of infection can lead to the improper disposal and use of used syringes in such urban areas, as indicated by a study that showed that $37.4 \%$ of the people in urban areas disposed of used syringes in the general house trash [13]. Furthermore, the students in our study were lacking in their knowledge of the transmission of HBV related to tattooing and body piercing by contrast with $45 \%$ of the students in Lahore [12]. Some 66.7\% of the study sample also did not recognize blades and razors of barbers as a cause of spread of HBV in contradistinction with $75.6 \%$ of the students in Lahore being aware of this fact [12]. Despite the lack of awareness of the students in Karachi, they were at par with the students in Lahore with respect to the percentage of people vaccinated [12]. However, when compared to general public [14], nonmedical students in our study had the correct belief that HBV was not spread through contaminated water $(70 \%)$ or contaminated food (67\%).

In Pakistan, percentage prevalence of HCV is $5.09 \%$ [10] in the general adult population. Despite this, a considerably low $51.76 \%$ of the nonmedical students in this study correctly identified the modes of transmission of this disease as distinct from only $32.15 \%$ patients attending family medicine clinics in Karachi [15]. Needle-stick injuries are the most wellknown factor in the spread of HCV. Despite this, only $38.2 \%$ of the nonmedical students were aware of this mode of transmission. This was in stark contrast to the correct knowledge of $94.7 \%$ people at a health awareness session according to Minaam et al. [14].

Another very important and rampant cause of HCV transmission is the use of unsterilized dental and surgical equipment. It was alarming to see that only $37 \%$ of the students correctly identified these as risk factors, by contrast with $87.7 \%$ [14] of the educated population.
Barbers in Pakistan have been identified as important contributors to the spread of HCV as shown by Janjua and Nizami [16] in their study of awareness levels of barbers, which was low (13\%) as expected. Not surprisingly, only 36.2\% students correctly identified sharing razors and blades as a risk factor. On the other hand, 86\% [14] subjects in the study by Minaam et al. proved well acquainted with this mode of spread. Another well-known culprit in propagation of HCV is sexual contact, and contact with blood and body secretions. This was not well known to our participants, because only $44.4 \%$ and $31.2 \%$, respectively, were conscious of this reality. However, most of the subjects in the study by Minaam et al. (83.2\%) [14] knew of the sexual route of transmission, while they were poorly aware of transmission by blood and body secretions. A similar study was conducted in Turkey [17] where 66\% and 90\% household contacts of hepatitis patients correctly identified sexual and parenteral mode of transmission, respectively.

\section{Conclusion}

Our study highlights a prominent lack of awareness regarding the different types of hepatitis $\mathrm{B}$ and $\mathrm{C}$ virus infection in the student community of nonmedical universities in Karachi. The level of awareness in the general population might actually be a lot lower than the same in the targeted population in our study. Currently, knowledge transfer by means of newspaper, pamphlets, banners, and television are not utilized effectively, either because of limitations of language differences throughout the country, affordability, or illiteracy among the general public [18]. Hence, there is an immediate need to conduct nationwide awareness programs through all possible mediums to raise the awareness of HBV and HCV in the Pakistani population. This is one effective way to combat the endemic of HBV and HCV infection.

\section{Acknowledgments}

The authors thank Prof. Rana Masood, Head of Department Medical Unit 5, Civil Hospital Karachi.

None of the authors have any conflict of interest to declare.

\section{References}

1. Hepatitis B. World Health Organization. [on line]. Revised March 2015. [cited 2015 March 30]; Available from: http://www.who.int/mediacentre/factsheets/ 
fs204/en/index.html

2. "FAQ about Hepatitis B". Stanford School of Medicine. [online] 2015. [cited 2015 March 30]; Available from: http://liver.stanford.edu/education/ faq.html

3. Noorali S, Hakim ST, McLean D, Kazmi SU, Bagasra O. Prevalence of hepatitis B virus genotype D in females in Karachi, Pakistan. J Infect Dev Countries. 2008; 2:373-8.

4. Hakim ST, Kazmi SU, Bagasra O. Seroprevalence of hepatitis B and C genotypes among young apparently healthy females of Karachi, Pakistan. Libyan J Med. 2008; 3:66-70.

5. Ali M, Idrees M, Ali L, Hussain A, Ur Rehman I, Saleem S, et al. Hepatitis B virus in Pakistan: A systematic review of prevalence, risk factors, awareness status and genotypes. Virology J. 2011; 8: 102-ff.

6. Alam MM, Zaidi SZ, Malik SA, Naeem A, Shaukat S, Sharif S, et al. Serology based disease status of Pakistani population infected with hepatitis B virus. BMC Infect Diseases. 2007; 7:64.

7. Wands JR. Prevention of hepatocellular carcinoma. N Engl J Med. 2004; 351:1567-70.

8. Bill K, Porchet H, for the Debiopharm Group (Debiopharm, Lausanne, Switzerland) Clinical Update - Debio 025 in hepatitis C - Presentation of Phase IIa efficacy results [online] April 28, 2008. [cited 2009 April 30]; Available from: https://www. debiopharm.com/images/stories/files/pressrelease/ pressrelease_current/debio_025-phiia_results_ 28apr08.pdf

9. Centers for Disease Control and Prevention. Recommendations for prevention and control of hepatitis $\mathrm{C}$ virus (HCV) infection and $\mathrm{HCV}$ related chronic disease. MMWR Recomm Rep. 1998; 47:1-39.

10. Mahmood Z, Abbasi SZ, Kardar AA, Rafi SMT. Prevalence of hepatitis B and C in patients admitted in ENT Ward, JPMC, Karachi. Pak J Otol. 2010; 26:7-9.

11. Nasim S, Shahid A, Pirzada AG, Memon AA. Perception of adolescent females about viral hepatitis in urban and rural Sindh. Pak J Med Res. 2009; 48:71-3.

12. Razi A, ur Rehman R, Naz S, Ghafoor F, Ullah Khan MA. Knowledge, attitudes and practices of university students regarding Hepatitis B and C. ARPN J Agricult Biomed Sci. 2010; 5:38-43.

13. Riaz H, Riaz S, Aziz S, Rajper J, Noorulain W. Methods of disposal of used syringes by hepatitis B and C patients at an urban and rural setting. JPMA. 2012: $62 ; 81$.

14. Minaam A, Muhammad F, Ahmed H, Sajjad R, Lubna S. Frequency and awareness of hepatitis B and C in visitors of hepatitis awareness Mela J Pak Med Assoc. 2010; 60:1069-71.

15. Khuwaja AK, Qureshi R, Fatmi Z. Knowledge about hepatitis B and C among patients attending family medicine clinics in Karachi. East Mediterr Health J. 2002; 8:787-93.

16. Janjua NZ, Nizamy MAM. Knowledge and practices of barbers about hepatitis B and C transmission in Rawalpindi and Islamabad. J Pak Med Assoc. 2004; 54:116-9.

17. Arzu T, Ö zlen A, Nurdan T. Awareness of hepatitis C virus transmission routes among patients, their household contacts and health care staff: Does perception match the reality? Turk J Gastroenterol. 2009; 20:104-7.

18. Jiwani N, Gul R. A silent storm: hepatitis C in Pakistan. J Pak Med St. 2011; 1:89-91. 